\title{
RUSSISCH-DEUTSCHES WÖRTERBUCH
}

unter Leitung und Redaktion von $\mathbf{H}$. H. Bielfeldt

14., durchgesehene Auflage

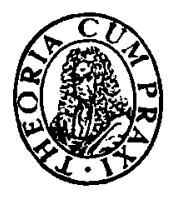

AKADEMIE-VERLAG - BERLIN 1982 


\section{Lizenzausgabe für:}

Kunst und Wissen Erich Bieber GmbH

Dufourstraße 51, Ch-8008 Zürich

Kunst und Wissen Erich Bieber OHG

Wilhelmstraße 4, D-7000 Stuttgart 1

Erschienen im Akademie-Verlag, DDR-1086 Berlin, Leipziger Straße 3-4

(C) Akademie-Verlag Berlin, 1958

Letzte Bearbeitung 1982

Lizenznummer : $202 \cdot 100 / 158 / 82$

Offsetnachdruck: VEB Druckerei „Thomas Müntzer“, 5820 Bad Langensalza

Bestellnummer : 7509963 (2040-S/2) - LSV 0857

Printed in GDR 